УДК 631.4

\title{
ВЛИЯНИЕ ТОРФЯНЫХ ПРЕПАРАТОВ НА ФОРМИРОВАНИЕ ЛАБИЛЬНОГО ОРГАНИЧЕСКОГО ВЕЩЕСТВА В ПРОЦЕССЕ БИОЛОГИЧЕСКОЙ РЕКУЛЬТИВАЦИИ
}

\author{
() Т.И. Бурмистрова ", Т.П. Алексеева, Л.И. Сысоева, Н.М. Трунова \\ Сибирский научно-исследовательский институт сельского хозяйства \\ и торфра, ул. Гагарина, 3, Томск, 634050 (Россия), e-mail: sibniit@mail.tomsknet.ru
}

На основе полевых исследований установлена эффективность торфяных препаратов в биологической рекультивации пород угольного отвала. За пять вегетационных периодов сформировался пул лабильного органического вещества. Вновь сформированное лабильное органическое вещество отличается по своей структуре от лабильного органического вещества зональной почвы. вещество.

Ключевые слова: биологическая рекультивация, торфяной препарат, угольный отвал, лабильное органическое

\section{Введение}

Для Кузбасса с его кризисной экологической обстановкой рекультивация земель, нарушенных в результате добычи угля, чрезвычайно актуальна.

Открытый способ разработки угольных месторождений, распространенный в Кузбассе, приводит к полному уничтожению на значительных территориях естественного биоценоза, на поверхность выносятся глубинные горные породы с низкой биогенностью, граничащей со стерильностью, что отрицательно сказывается на росте и развитии растений [1].

Развитие почвенного профиля в техногенных ландшафтах происходит очень медленно, и задачей рекультивации техногенного грунта является восстановление его биологических функций, возобновление и ускорение почвообразовательного процесса, создание устойчивых фитоценозов.

Начальный этап почвообразования связан с появлением растительности, преобразованием растительного материала и, как следствие, накоплением лабильного органического вещества (ЛОВ), представляющего собой органические остатки разной степени разложения и гумификации, служащие непосредственным и наиболее доступным источником питания растений и микроорганизмов [2].

Для создания условий роста и развития растений, активации биологических процессов в грунте, возможно использовать препараты на основе торфа.

Цель настоящей работы - исследование некоторых свойств ЛОВ, образовавшегося на поверхности

Бурмистрова Татьяна Ивановна - зав. лабораторией ЛФХИ, старший научный сотрудник, кандидат химических наук, тел.: (3822) 52-75-41, e-mail: burmistrova@ sibniit.tomsknet.ru Алексеева Татьяна Петровна - старший научный сотрудник, кандидат химических наук, тел.: (3822) 52-75-41, e-mail: sibniit@mail.tomsknet.ru Сысоева Лидия Николаевна - старший научный сотрудник, кандидат химических наук, тел.: (3822) 52-75-41, e-mail: sibniit@ mail.tomsknet.ru Трунова Нина Максимовна - старший научный сотрудник, тел.: (3822) 52-75-41, e-mail: sibniit@mail.tomsknet.ru отвальной породы за пять вегетационных периодов при выращивании бобовых и злаковых трав с использованием торфяных препаратов.

\section{Экспериментальная часть}

Для исследования свойств ЛОВ нами привлечены методы потенциометрического титрования, фотоколориметрический, ИК-спектроскопический (прибop Nicolet 6700 FT-IR, приставка НПВО кристаллалмаз, спектральный диапазон 400-4000 $\mathrm{cm}^{-1}$.

\footnotetext{
* Автор, с которым следут вести переписку.
} 
Используемые торфяные препараты - органоминеральное удобрение [3] (торфяной мелиорант) и оксигумат [4] - являются источником органического вещества и микрофлоры. Наличие в составе препаратов продуктов гидролитической деструкции торфа обеспечивает им свойства адаптогенов, стимуляторов роста растений, и, как следствие, в неблагоприятных условиях торфяные препараты создают растениям условия для выживания.

Опыт по биологической рекультивации с использованием торфяных препаратов проводили в течение пяти вегетационных периодов на спланированном участке угольного отвала возраста 25 лет разреза Краснобродский Кемеровской области.

Грунт отвальной породы (ГО) представлен песчаниками и глинистыми породами (алевролитами, аргиллитами) и в незначительной степени - непромышленными прослоями угля. По агрохимическим показателям и содержанию токсичных элементов [5] грунт пригоден для биологической рекультивации.

В качестве травяной культуры выбрана смесь бобовых и злаковых трав. Доза внесения торфяного мелиоранта (ТМ) в грунт отвала составила 25 т/га; концентрация оксигумата, используемая в варианте с обработкой семян и вегетирующих растений, - 0,005\% по гуминовым кислотам.

Для исследования использованы следующие варианты опыта: 1) грунт отвала (ГО); 2) ГО + торфяной мелиорант (ТМ), 25 т/га; 3) ГО + обработка семян и вегетирующих растений оксигуматом (ОГ).

Извлечение ЛОВ из почвы и грунта опытных вариантов проводили 0,1 M раствором $\mathrm{NaOH}$ [6]. Для определения содержания углерода лабильного органического вещества (С по ЦИНАО (ГОСТ 26213-91) с фотометрическим окончанием [7]. Исследование оптических свойств ЛОВ проводили согласно рекомендациям Д.С. Орлова [8].

Для определения в составе ЛОВ различных по природе функциональных групп кислотного характера применяли широко используемый для этой цели метод обратного потенциометрического титрования [9].

\section{Обсуждение результатов}

Анализ электронных спектров поглощения ЛОВ исследуемых образцов грунта, образовавшегося за пять вегетационных периодов, показал, что спектры по характеру идентичны и представляют собой пологие кривые (рис. 1). При этом оптическая плотность ЛОВ грунта в измеряемой области спектра оказалась выше в случае варианта с использованием ТМ, самая низкая - в контрольном варианте. На основании вышеизложенного можно предположить, что в направлении от зональной почвы к грунту с использованием ТМ и далее с использованием ОГ уменьшается вклад ароматических структур в построение ЛОВ.

Об этом же свидетельствуют и величины коэффициента цветности А (табл.), который характеризует степень конденсированности органического вещества. Сложную структуру имеет ЛОВ зональной почвы, а новообразованное ЛОВ в вариантах с использованием торфяных препаратов в большей степени обогащено алифатическими структурами.

В случае вариантов с использованием торфяных препаратов коэффициент цветности А хорошо согласуется со спектрофотометрическими кривыми. Чем выше коэффициент А, тем ниже оптическая плотность, и соответственно ниже располагается спектрофотометрическая кривая. Исключение составляет ЛОВ грунта отвальной породы. В этом случае значение коэффициента А ниже, чем в случае вариантов с использованием торфяных препаратов. Ниже и оптическая плотность во всем рассматриваемом интервале длин волн (рис. 1). Данное обстоятельство может быть обусловлено количеством хромофорных групп в ЛОВ грунта рассматриваемых вариантов, а также природой извлекаемого из грунтов ЛОВ. Если ЛОВ в вариантах с использованием торфяных препаратов обусловлено в основном продуктами деструкции растительного материала, то ЛОВ грунта отвальной породы - продуктами деструкции угольных частиц.

Влияние торфяных препаратов на показатели структуры лабильного органического вещества

\begin{tabular}{l|c|c|c|c}
\hline \multirow{2}{*}{\multicolumn{1}{c|}{ Показатели }} & \multicolumn{3}{|c}{ Варианты опыта } \\
\cline { 2 - 5 } & зональная почва & грунт отвала (образец 1) & ГО + ТМ (образец 2) & ГО + ТМ (образец 3) \\
\hline $\begin{array}{l}\text { Коэффициент цветности А } \\
\left(\lambda_{1}, \lambda_{2}=400 / 500 н м\right)\end{array}$ & 1,78 & 2,27 & 2,54 & 2,73 \\
$\begin{array}{l}\text { Сддержание кислотных } \\
\text { функциональных групп, } \\
\text { ммоль/г }\end{array}$ & 0,38 & - & 0,54 & 0,54 \\
\hline
\end{tabular}


Рис. 1. Зависимость оптической плотности от длины волны в образцах грунта:

П - почва; 1 - грунт отвала (ГО); 2 - ГО + торфяной мелиорант (ТМ), 25 т/га; 3 - ГО + обработка семян и вегетирующих растений оксигуматом (ОГ)

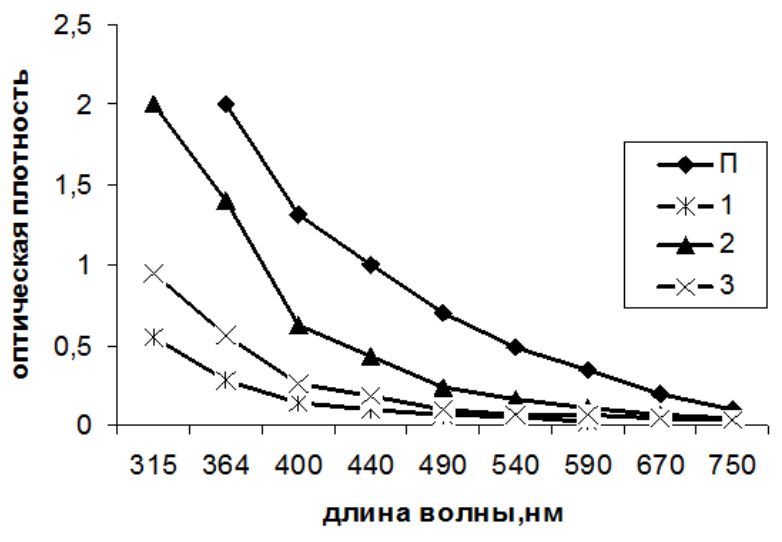

Сравнение условий проведения биологической рекультивации угольного отвала на содержание функциональных групп кислотного характера в составе ЛОВ, образующегося в процессе деструкции растительных остатков, позволяет оценить степень его сформированности по сравнению с зональной почвой.

Вследствие сложного состава ЛОВ наклон кривой потенциометрического титрования вблизи точки эквивалентности зависит от многих факторов, в том числе от гидролиза солей, растворимости осадков. Поэтому для более корректного фиксирования точки эквивалентности при титровании кислотных функциональных групп в исследуемых объектах были сняты дифференциальные кривые в координатах $\mathrm{dpH} / \mathrm{dV}$ от объема титранта $\mathrm{V}(\mathrm{HCl})$ и определено содержание функциональных групп в составе ЛОВ. Экспериментальные результаты представлены в таблице.

Анализ результатов свидетельствует о том, что ЛОВ, образующиеся при деструкции растительных остатков в грунте отвальной породы (образцы 2, 3), являются менее структурированными, чем в зональной почве, где содержание кислотных функциональных групп значительно меньше. Это обусловлено тем, что в зональной почве как более стабильной системе межмолекулярные и внутримолекулярные взаимодействия ионизированных групп приводят к образованию достаточно прочных структур, которые не разрушаются при титровании $\mathrm{HCl}$ и в связи с этим не могут быть оттитрованы. А в грунте отвальной породы образующиеся продукты деструкции растительных остатков далеки от состояния равновесия, и кислотные функциональные группы, представленные этими продуктами распада, прекрасно титруются, их количество представлено в таблице.

Для подтверждения вышесказанного были сняты ИК-спектры образцов ЛОВ зональной почвы (ЗП) и варианта (ГО + ТМ) (рис. 2). Известно [10], что если в ИК-спектре карбоксилсодержащих объектов при титровании кислотных групп (почва, торф, карбоксильные катиониты и др.) имеется одна широкая полоса поглощения ионизованной карбоксильной группы при 1540-1680 см ${ }^{-1}$, то принято считать, что все кислотные группы, в частности карбоксильные, оттитрованы. О частичной нейтрализации кислотных групп свидетельствует наличие в ИК-спектре полосы поглощения карбонильной группы $\mathrm{C}=\mathrm{O}$.

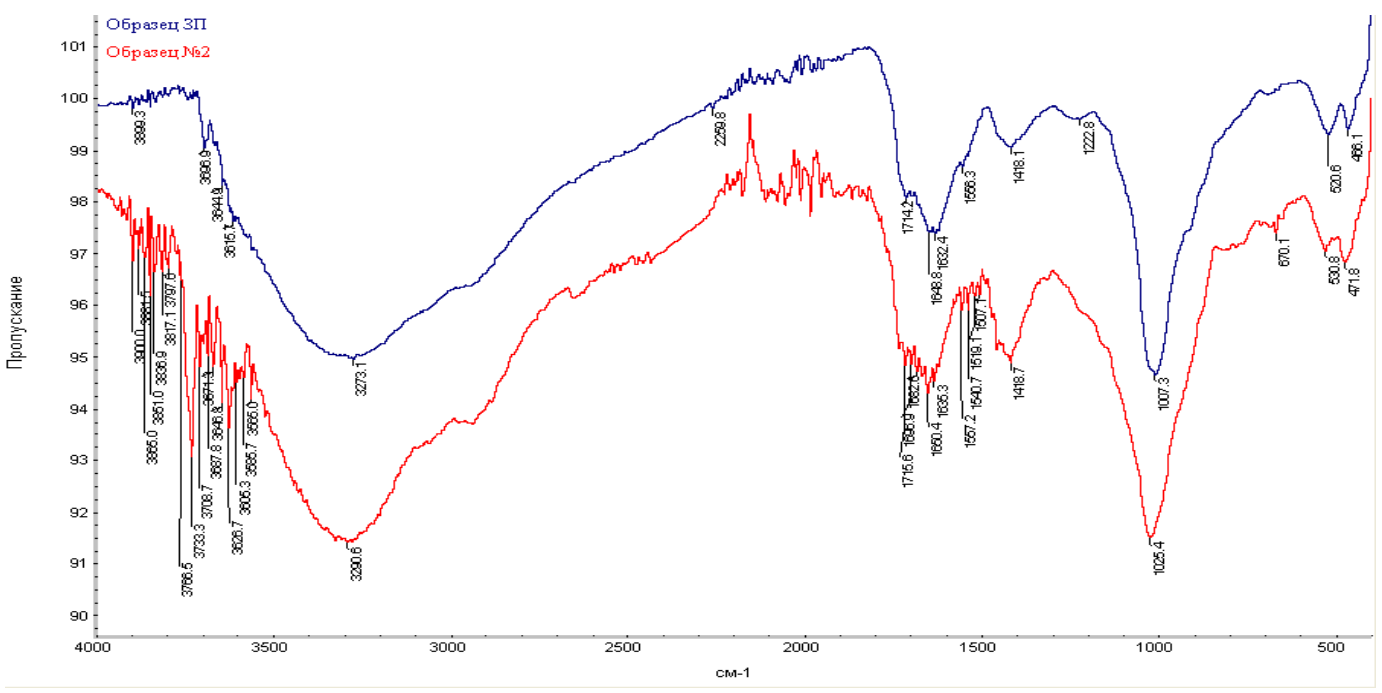

Рис. 2. ИК-спектры образцов ЛОВ зональной почвы и варианта (ОГ + ТМ,25т/га) 
В нашем случае ИК-спектр ЗП во всем диапазоне является более структурированным по сравнению с ИК-спектром образца 2, особенно это проявляется в области поглощения валентных колебаний карбонильной / карбоксильной группы при $1540-1715 \mathrm{~cm}^{-1}$, которая может быть представлена кетонами, альдегидами, карбоновыми кислотами и их функциональными производными. Наличие в ИК-спектре ЗП ярко выраженной полосы поглощения карбонильной группы $\mathrm{C}=\mathrm{O}$ при $1714 \mathrm{~cm}^{-1}$ свидетельствует о неполной нейтрализации кислотных групп в образце. В ИК-спектре образца 2 (ГО + ТМ) эта полоса отсутствует. Это является подтверждением заниженного результата по титрованию кислотных групп в зональной почве.

\section{Выводы}

В полевом опыте, проводимом на угольном отвале разреза Краснобродский Кемеровской области, показано, что за пять вегетационных периодов при выращивании травяных культур с использованием торфяных препаратов сформировался пул лабильного органического вещества. ЛОВ непосредственно участвует в питании растений, служит энергетическим материалом для почвенных микроорганизмов, обеспечивая стабильное развитие фитоценозов, но вновь сформированное ЛОВ отличается по своей структуре от ЛОВ зональной почвы, о чем свидетельствуют результаты проведенного исследования.

\section{Список литературь}

1. Баранник Л.П., Шмонов А.М. Проблемы лесной рекультивации в Кузбассе // Рекультивация нарушенных земель в Сибири. Кемерово, 2005. Вып. 1. С. 54-62.

2. Мамонтов В.Г., Афанасьев Р.А., Радионова А.П., Быканова О.М. К вопросу о лабильном органическом веществе почв // Плодородие. 2008. №2. С. 20-22.

3. Патент 228607 (РФ). Органоминеральное удобрение / Т.П. Алексеева, Л.Н. Сысоева, Н.М. Трунова, Т.И. Бурмистрова. Опубл. 27.08.06.

4. Патент №2216175 (РФ). Способ получения средств защиты от грибковых заболеваний / Т.И. Бурмистрова, Л.Н. Сысоева, Н.М. Трунова, Н.Н. Терещенко. Опубл. 20.11.03.

5. Алексеева Т.П., Сысоева Л.Н., Бурмистрова Т.И., Трунова Н.М. Исследование эффективности применения торфяного мелиоранта для биологической рекультивации угольных отвалов // Достижения науки и техники АПК. 2010. №12. С. 34-36.

6. Александрова Л.Н. Органическое вещество почвы и процессы трансформации. Л., 1980.510 с.

7. ГОСТ 26213-91. Почва. Методы определения органического вещества. М., 1991. С. 1-6.

8. Орлов Д.С., Гришина Л.А. Практикум по химии гумуса. М., 1981. 271 с.

9. Александрова Л.Н., Найденова О.А. Лабораторно-практические занятия по почвоведению. Л., 1986. 295 с.

10. Кросс А. Введение в практическую инфракрасную спектроскопию. М., 1961. 111 с.

Поступило в редакичию 5 июля 2013 2. 
Burmistrova T.I. , Alexeeva T.P., Sysoeva L.N., Trunova N.M. IMPACT PEAT COMPOSITIONS ON LABILE ORGANIC MATTER FORMATION IN RECULTIVATION OF ROCKS CARBON REFUSE

Institute of Agriculture and Peat of Russia Agriculture Academy, Gagarina st., 3, Tomsk, 634050 (Russia), e-mail: sibniit@mail.tomsknet.ru

Efficiency of peat ameliorant in biological recultivation of rocks carbon refuse on the basis of field research was established. Pool of labile organic matter has been formed for five vegetative seasons. Newly-formed labile organic matters vary from labile organic matter of zonal soil in formation.

Keywords: biological recultivation, peat composition, carbon refuse, labile organic matter.

\section{References}

1. Barannik L.P., Shmonov A.M. Rekul'tivatsiia narushennykh zemel'v Sibiri. [Reclamation of disturbed lands in Siberia]. Kemerovo, 2005, no. 1, pp. 54-62. (in Russ.).

2. Mamontov V.G., Afanas'ev R.A., Radionova A.P., Bykanova O.M. Plodorodie, 2008, no. 2, pp. 20-22. (in Russ.).

3. Patent 228607 (RU). 27.08.06. (in Russ.).

4. Patent 216175 (RU). 20.11.03. (in Russ.).

5. Alekseeva T.P., Sysoeva L.N., Burmistrova T.I., Trunova N.M. Dostizheniia nauki i tekhniki APK. [Advances in science and technology of agriculture]. 2010, no. 12, pp. 34-36. (in Russ.).

6. Aleksandrova L.N. Organicheskoe veshchestvo pochvy i protsessy transformatsii. [Soil organic matter and transformation processes]. Leningrad, 1980, 510 p. (in Russ.).

7. GOST 26213-91. Pochva. Metody opredeleniia organicheskogo veshchestva. [State Standard 26213-91. Soil. Methods for determination of an organic substance]. Moscow, 1991, pp. 1-6. (in Russ.).

8. Orlov D.S., Grishina L.A. Praktikum po khimii gumusa. [Workshop on the chemistry of humus]. Moscow, 1981, 271 p. (in Russ.).

9. Aleksandrova L.N., Naidenova O.A. Laboratorno-prakticheskie zaniatiia po pochvovedeniiu. [Laboratory and practical training in soil science]. Leningrad, 1986, 295 p. (in Russ.).

10. Kross A. Vvedenie v prakticheskuiu infrakrasnuiu spektroskopiiu. [Introduction to practical infrared spectroscopy]. Moscow, 1961, 111 p. (in Russ.).

Received July 5, 2013

\footnotetext{
* Corresponding author.
} 
